\title{
Regulation of Procollagen Metabolism in the Pressure-overloaded Rat Heart
}

\author{
Elias G. Eleftheriades, * Jean-Bernard Durand, * Alan G. Ferguson, * Gary L. Engelmann, * \\ Stephen B. Jones, ${ }^{\star}$ and Allen M. Samarel ${ }^{\star \star}$ \\ Departments of ${ }^{*}$ Medicine and ${ }^{\ddagger}$ Physiology, Loyola University of Chicago, Stritch School of Medicine, Maywood, Illinois 60153
}

\begin{abstract}
To determine the molecular events responsible for the disproportionate accumulation of myocardial fibrillar collagens during sustained hypertension, we examined the in vivo rate of procollagen synthesis, collagen accumulation, and intracellular procollagen degradation 1-16 wk after abdominal aortic banding in young rats. These measurements were correlated with tissue mRNA levels for type I and type III procollagen polypeptides. Banded animals developed moderate, sustained hypertension and mild left ventricular hypertrophy. Increased type III procollagen mRNA levels were detected early after banding and persisted for the entire observation period. Disproportionate collagen accumulation without histological evidence of $\mathbf{f}$ brosis was noted within 1 wk after hypertension induction. Fibrillar collagen accumulation at this time point resulted not from a major increase in procollagen synthesis, but rather a marked decrease in the rate of intracellular procollagen degradation. Interstitial fibrosis, however, was observed 16 wk after banding. Type I procollagen mRNA levels were increased sixfold, but only after 16 wk of hypertension. These results correlated well with the results of in vivo procollagen synthesis experiments at $16 \mathrm{wk}$, which demonstrated a threefold increase in left ventricular procollagen biosynthesis. We conclude that pretranslational as well as posttranslational mechanisms regulate fibrillar collagen deposition in the myocardial extracellular matrix during sustained hypertension. (J. Clin. Invest. 1993. 91:1113-1122.) Key words: extracellular matrix • fibrosis • hypertension • hypertrophy • gene expression
\end{abstract}

\section{Introduction}

The myocardial extracellular matrix is organized into an elaborate three-dimensional network that is intimately associated with cardiac function (1). This complex arrangement of connective tissue provides a stress-tolerant elastic skeleton that serves to direct, transmit, and distribute the contractile force generated by individual cardiac muscle cells and to maintain capillary patency throughout the cardiac cycle (2). The major components of the cardiac interstitium are fibrillar collagens, which comprise 3-6\% of myocardial dry weight and consist mainly of type I and type III collagens.

Address correspondence to A. M. Samarel, M.D., Department of Medicine, Loyola University Medical Center, 2160 South First Ave., Maywood, IL 60153.

Received for publication 9 July 1992 and in revised form 2 October 1992.

J. Clin. Invest.

(c) The American Society for Clinical Investigation, Inc.

$0021-9738 / 93 / 03 / 1113 / 10 \quad \$ 2.00$

Volume 91, March 1993, 1113-1122
Whereas a great deal is known about the regulation of contractile protein gene expression by cardiac myocytes, very little information is currently available regarding the regulation of procollagen gene expression by cardiac fibroblasts. It is these nonmuscle cells (rather than cardiac myocytes) that are believed to be exclusively responsible for the production and deposition of fibrillar collagens within the cardiac extracellular matrix (3). Cardiac fibrillar procollagen genes are expressed throughout adult life, and their products are continuously synthesized and degraded, albeit at slow rates (4). Whereas fibrillar collagens normally accumulate in the cardiac interstitium during aging (5), a variety of pathophysiological conditions have been associated with disproportionate collagen accumulation and associated abnormalities in contractile function. For instance, cardiac hypertrophy induced by pressure overload in the rat (6-11) and in the nonhuman primate (12) has been associated with disproportionate collagen accumulation and/ or histological evidence of interstitial fibrosis. However, the molecular mechanisms responsible for collagen accumulation during ventricular overload are poorly understood. Chapman et al. (9) demonstrated increased mRNA levels for $\alpha_{2}$ (I), and $\alpha_{1}$ (III) procollagen polypeptides in the rat myocardium during the first week after abdominal aortic coarctation. Villarreal and Dillmann (11) showed a similar transient increase in left ventricular $(\mathrm{LV})^{1}$ procollagen mRNA levels (preceded by increased mRNA's encoding TGF $\beta_{1}$ and the IIIA+ isoform of fibronectin) immediately after thoracic aortic banding. However, collagen accumulation and interstitial fibrosis (as detected by immunofluorescence light microscopy) was observed only at much later stages of experimental hypertension. In fact, procollagen production by noncardiac fibroblasts in culture is known to be regulated at several levels, including posttranscriptional, translational, and posttranslational steps in gene expression (for review see reference 13). Indeed, an interesting aspect of the biosynthesis, processing and turnover of fibrillar collagens, is that a significant proportion $(10-90 \%$ in various cell culture systems and in vivo) of newly synthesized procollagens undergo rapid degradation before or soon after their secretion $(4,14)$. Thus there are numerous potential sites for the regulation of cardiac fibrillar collagen accumulation in both the normal and pressure-overload heart.

In the present report we have examined the relationships between mRNA levels encoding cardiac fibrillar procollagen polypeptides, in vivo procollagen synthesis, and collagen accumulation 1-16 wk after imposition of $\mathrm{LV}$ pressure overload in the juvenile rat. In contrast to previous studies of procollagen gene expression during pressure overload, younger animals were used to produce a more gradual onset of sustained hypertension to minimize acute myocardial injury. More impor-

1. Abbreviations used in this paper: GADPH, glyceraldehyde 3-phosphate dehydrogenase; LV, left ventricular; MAP, mean arterial pressure. 
tantly, we have used a modification (15) of the proline flooding infusion method (16) to assess cardiac procollagen synthesis in vivo and to relate alterations in mRNA levels to changes in procollagen production and accumulation over time. This biosynthetic labeling method allows for the accurate measurement of procollagen synthesis in the intact animal, as well as an estimate of the proportion of newly synthesized cardiac procollagens subject to rapid intracellular degradation (4). Thus the amounts of fully processed collagens that are ultimately secreted and deposited in the extracellular space can be determined (15). Evidence is presented in this report to indicate that alterations in procollagen synthesis and intracellular degradation are both important in the complex regulatory events responsible for cardiac extracellular matrix remodeling during sustained hypertension.

\section{Methods}

Reagents. L- $\left[2,3-{ }^{3} \mathrm{H}\right]$ proline $(35 \mathrm{Ci} / \mathrm{mmol}),\left[\gamma_{-}{ }^{32} \mathrm{P}\right] \mathrm{ATP}$ and $[\alpha-$ ${ }^{32} \mathrm{P}$ ]dCTP were obtained from Amersham Corp. (Arlington Heights, IL). L-[U- $\left.{ }^{14} \mathrm{C}\right]$ proline $(250 \mathrm{mCi} / \mathrm{mmol})$ was purchased from ICN Pharmaceuticals, Inc. (Costa Mesa, CA). $\left[\mathrm{N}\right.$-methyl- $\left.{ }^{14} \mathrm{C}\right]$ dansyl chloride $(112 \mathrm{mCi} / \mathrm{mmol}$ ) was purchased from RPI International (Rolling Meadows, IL $).\left[{ }^{14} \mathrm{C}\right]$ hydroxyproline $(6 \mathrm{mCi} / \mathrm{mmol})$ was isolated from collagen hydrolysates obtained from cultured neonatal rat cardiac fibroblasts that were biosynthetically labeled with $\left[{ }^{14} \mathrm{C}\right]$ proline. $O$-phthaldehyde (OPA) was obtained from Pierce Chemical Co. (Rockford, IL). All other reagents were of the highest grade commercially available and were obtained from Sigma Chemical Co. (St. Louis, MO) and Baxter Scientific Products (McGaw Park, IL).

Experimental animals. Male Sprague-Dawley rats (Harlan Sprague Dawley, Inc., Indianapolis, IN) weighing $160-170 \mathrm{~g}$ were anesthetized with an intramuscular injection of ketamine $(90 \mathrm{mg} / \mathrm{kg})$ and xylazine $(10 \mathrm{mg} / \mathrm{kg})$. Constriction of the suprarenal abdominal aorta was produced using a tantalum hemoclip (Edward Weck \& Co., Research Triangle Park, NC). The applicator was modified to allow passage of a 25 -gauge needle through the hemoclip when completely closed. Shamoperated animals underwent dissection of the abdominal aorta without application of the suprarenal band. Postoperatively, all animals received food and water ad libitum. Sham and banded animals were investigated at $1,2,4,8$, and $16 \mathrm{wk}$ after surgery (minimum of five animals in each group).

Blood pressure measurements. Rats were anesthetized with halothane inhalation ( $2 \%$ in $\mathrm{O}_{2}$ ) and a fluid-filled, heparinized PE-50 catheter was inserted to the level of the aortic arch via the left carotid artery. The catheter was tunneled to exit in the intrascapular region, and the animals were allowed to recover from anesthesia for $\geq 2.5 \mathrm{~h}$. Mean arterial pressure (MAPs) were recorded using a pressure transducer (Gould-Statham, Cleveland, $\mathrm{OH}$ ) attached to a pen-writing oscillograph.

Quantitative analysis of procollagen $m R N A$ levels. Portions of LV tissue (200-300 mg) were homogenized with a Polytron homogenizer in a solution containing $4 \mathrm{M}$ guanidinium thiocyanate, and total RNA $(100-150 \mu \mathrm{g})$ was isolated according to the method of Chomczynski and Sacchi ( 17). RNA was quantified by absorbance at $260 \mathrm{~nm}$ and the integrity was determined by examining the $28 \mathrm{~S}$ and $18 \mathrm{~S}$ rRNA bands in ethidium bromide-stained agarose gels visualized under ultraviolet (UV) light. Total RNA (20 $\mu \mathrm{g})$ was denatured $\left(60^{\circ} \mathrm{C}, 10 \mathrm{~min}\right)$ and size-fractionated by electrophoresis on $1 \%(\mathrm{wt} / \mathrm{vol})$ agarose gels under denaturing conditions. RNA was subjected to partial alkaline hydrolysis, transferred to nylon membranes (MSI, Westboro, MA) in 10X SSC, and immobilized by UV irradiation. Hybridization with cDNA probes was performed overnight at $42^{\circ} \mathrm{C}$ in buffer containing $50 \%$ formamide, $10 \%$ ( vol $/ \mathrm{vol}$ ) dextran sulfate, $1 \%(\mathrm{wt} / \mathrm{vol}$ ) SDS, $1 \mathrm{M} \mathrm{NaCl}$, and $100 \mu \mathrm{g} / \mathrm{ml}$ denatured salmon sperm DNA. The following cDNA clones were used: Human Collagen Type I, alpha $1\left[\alpha_{1}(I)\right]$, clone
Hf677 ( 18); Human Collagen Type III, alpha 3 [ $\alpha_{1}$ (III)], clone Hf934 (19); and human glyceraldehyde 3-phosphate dehydrogenase (GAPDH), clone pHcGAP (20). All cDNAs were obtained from the American Type Culture Collection (Rockville, MD). Inserts of procollagen cDNA clones were isolated by restriction enzyme digestion and labeled by random primer extension with $\left[\alpha-{ }^{32} \mathrm{P}\right] \mathrm{dCTP}\left({ }^{32} \mathrm{P}\right.$-labeled to $>10^{9} \mathrm{cpm} / \mu \mathrm{g}$ ). The GAPDH plasmid cDNA was labeled by nick translation using $\left[\alpha-{ }^{32} \mathrm{P}\right] \mathrm{dCTP}\left({ }^{32} \mathrm{P}\right.$-labeled to $\left.>10^{9} \mathrm{cpm} / \mu \mathrm{g}\right)$. Blots were washed in $2 \times \mathrm{SSC}-0.5 \% \mathrm{SDS}\left(25^{\circ} \mathrm{C}, 20 \mathrm{~min}\right)$ and $0.1 \times \mathrm{SSC}-0.1 \%$ $\operatorname{SDS}\left(65^{\circ} \mathrm{C}, 30 \mathrm{~min}\right)$. Equal loading conditions for the Northern blots were verified by hybridizing the filters with an oligonucleotide for rat 18 S rRNA (5'-ACGGTATCTGATCGTCTTCGAACC-3') (21). The oligonucleotide probe was end labeled with $\left[\gamma_{-}{ }^{32} \mathrm{P}\right] \mathrm{ATP}$ using T4 kinase. Hybridization with $1 \times 10^{6} \mathrm{cpm} / \mathrm{ml}$ of labeled oligonucleotide was performed overnight at $51^{\circ} \mathrm{C}$ in a solution containing $6 \times \mathrm{SSC}, 1 \times$ Denhardt's solution, $0.1 \%$ SDS, $0.05 \%$ Na pyrophosphate, $20 \mu \mathrm{g} / \mathrm{ml}$ tRNA, and $100 \mu \mathrm{g} / \mathrm{ml}$ denatured salmon sperm DNA. Washings were performed in $6 \times \mathrm{SSC}-0.1 \% \mathrm{SDS}$ at $65^{\circ} \mathrm{C}$ for $30 \mathrm{~min}$. All filters were exposed at $-80^{\circ} \mathrm{C}$ (for varying time periods) to Kodak XAR- 5 film using intensifier screens. Band intensity was quantified by laser densitometry (Ultrascan XL enhanced laser densitometer; LKB Instruments, Inc. [Gaithersburg, MD] interfaced to a personal computer running Gelscan XL Ver. 1.2). Procollagen mRNA levels were then expressed relative to the band intensity of the GAPDH mRNA.

Tissue fixation for light and electron microscopy. Anesthetized animals were injected via the inferior vena cava with heparin $(100 \mathrm{U} / 100$ $\mathrm{g}$ body wt) followed by $1 \mathrm{ml}$ of $3.3 \mathrm{M} \mathrm{KCl}$ to induce diastolic arrest and processed as previously described (22). Hearts were rapidly removed, rinsed with HBSS, trimmed of noncardiac tissue, and perfused via the aorta $\left(5 \mathrm{~min} ; 25^{\circ} \mathrm{C}\right)$ with $100 \mathrm{mM} \mathrm{Na}$ phosphate buffer, $\mathrm{pH}$ 7.4. The perfusate was then changed to $2 \%(\mathrm{wt} / \mathrm{vol})$ glutaraldehyde, and the hearts were perfused for an additional $15 \mathrm{~min}$. Hearts were removed from the cannula and $1-\mathrm{mm}$ cubes of $\mathrm{LV}$ myocardium were placed in the same fixative solution for $4-6 \mathrm{~h}$ at $4^{\circ} \mathrm{C}$. Samples were then washed three times and immersed in $7.5 \%$ sucrose overnight. Tissue samples were subsequently postfixed in freshly prepared $1 \% \mathrm{OsO}_{4}$ in $100 \mathrm{mM}$ $\mathrm{Na}$ cacodylate buffer, $\mathrm{pH} 7.4$, for $1 \mathrm{~h}$ at $4^{\circ} \mathrm{C}$, and washed five times with buffer and twice with distilled water. Tissue samples were then dehydrated in a graded series of ethanols, embedded in Epon resin, and polymerized overnight. Thick sections $(1 \mu \mathrm{m})$ were obtained from random blocks of each animal and used for light microscopy after toluidine blue staining. Thin sections were obtained from the same blocks, postsection stained with uranyl acetate and lead citrate, and imaged and photographed in an electron microscope (model H-600; Hitachi Ltd., Tokyo, Japan ).

Flooding infusion method. A modification (15) of the proline flooding infusion technique (16) was employed to estimate the fractional rate of $\mathrm{LV}$ procollagen synthesis in vivo. All infusions were performed between 0800 and 1200 to control for any diurnal variation in cardiac procollagen synthetic rates. The flooding tracer was prepared by mixing unlabeled proline $(2.8 \mathrm{M})$ and $\left[{ }^{3} \mathrm{H}\right]$ proline $(1 \mathrm{mCi} / \mathrm{ml}$ in $2 \%[\mathrm{vol} / \mathrm{vol}]$ ethanol; final $\left[{ }^{3} \mathrm{H}\right]$ proline specific radioactivity $=900$ $\mathrm{dpm} / \mathrm{nmol}$ ). Sham and banded rats were lightly anesthetized by ether inhalation. Each rat received $320 \mu \mathrm{Ci}$ of $\left[{ }^{3} \mathrm{H}\right]$ proline and $1.4 \mathrm{mmol}$ of unlabeled proline per $100 \mathrm{~g}$ body wt injected via the dorsal penile vein over a period of 1-2 min. $1 \mathrm{~h}$ after injection, rats were reanesthetized with ether, and a heparinized blood sample $(500 \mu \mathrm{l})$ was removed by cardiac puncture for determination of plasma proline specific radioactivity $\left(\mathrm{F}^{*}, \mathrm{dpm} / \mathrm{nmol}\right)(23)$. The heart was then rapidly excised, rinsed in iced $150 \mathrm{mM} \mathrm{NaCl}$, and frozen at $-80^{\circ} \mathrm{C}$. A stopwatch was used to time the period from the beginning of the bolus injection to cardiac extirpation.

Determination of total cardiac hydroxyproline specific radioactivity and concentration. Tissue homogenization was performed by modifications (15) of the method of McAnulty and Laurent (24). Briefly, frozen hearts from sham and banded rats used in procollagen synthesis experiments were thawed, rinsed in iced $150 \mathrm{mM} \mathrm{NaCl}$, trimmed of fat and great vessels, and weighed. Further dissection was performed to 
remove atria and valvular structures and to obtain LV (left ventricular free wall and septum) and right ventricular free wall wet weights. Precisely weighed portions of LV tissue $(400-500 \mathrm{mg})$ were homogenized in $9 \mathrm{vol}$ of water. After removal of $1 \mathrm{ml}$ of tissue homogenate for DNA and total protein analysis (see below), proteins in the remaining whole tissue homogenate were precipitated by addition of iced ethanol to a final concentration of $67 \%(\mathrm{vol} / \mathrm{vol})$. After centrifugation $(10,000 \mathrm{~g}$, $15 \mathrm{~min}$ ), the precipitate was washed once with $67 \%$ ( $\mathrm{vol} / \mathrm{vol}$ ) ethanol, and the combined supernatant fraction and washings were evaporated to dryness. The residue was then reconstituted in $2 \mathrm{ml}$ of $6 \mathrm{~N} \mathrm{HCl}$ and hydrolyzed $\left(110^{\circ} \mathrm{C}, 24 \mathrm{~h}\right)$. The precipitant fraction (after ethanol precipitation and washing) was resuspended in $4 \mathrm{ml}$ of $6 \mathrm{~N} \mathrm{HCl}$ and also hydrolyzed $\left(110^{\circ} \mathrm{C}, 24 \mathrm{~h}\right) \cdot\left[{ }^{14} \mathrm{C}\right]$ hydroxyproline tracer $(4,000 \mathrm{dpm})$ was added to each hydrolysis tube of both the tissue-free and proteinbound fractions to serve as an internal standard for calculating the recovery of $\left[{ }^{3} \mathrm{H}\right]$ hydroxyproline and unlabeled hydroxyproline (Pro$\mathrm{OH})$. The hydrolysates were evaporated to dryness, reconstituted, filtered, and reevaporated. Pro-OH and proline (Pro) were separated from the bulk of amino acids by $O$-phthaldehyde derivatization, as previously described (15). The final residue was resuspended in HPLC-grade water (200-400 $\mu \mathrm{l})$ and a portion of the tissue-free and protein-bound samples were removed for quantitative analysis of Pro$\mathrm{OH}$ using a colorimetric assay (25). The total amount of Pro-OH in these samples was corrected for losses during isolation by ${ }^{3} \mathrm{H}-{ }^{14} \mathrm{C}$ double label scintillation counting. Data were expressed as nanomoles of Pro-OH per gram wet weight for both tissue-free and protein-bound Pro-OH pools.

Separation of $\left[{ }^{3} \mathrm{H}\right]$ hydroxyproline $\left({ }^{3} \mathrm{H}-\mathrm{Pro}-\mathrm{OH}\right)$ from $\left[{ }^{3} \mathrm{H}\right]$ proline $\left({ }^{3} \mathrm{H}-\mathrm{Pro}\right)$ in the tissue-free and protein-bound hydrolysates was accomplished by cation-exchange HPLC (26). Fractions ( $1 \mathrm{ml}$ ) containing the $\left[{ }^{14} \mathrm{C}\right]$ hydroxyproline internal standard were identified by doublelabel scintillation counting and corrected for recovery of ${ }^{3} \mathrm{H}$-radioactivity. Data were expressed as dpm of ${ }^{3} \mathrm{H}-\mathrm{Pro}-\mathrm{OH}$ per $\mathrm{g}$ wet wt for both tissue-free and protein-bound pools. The total tissue hydroxyprolinespecific radioactivity $\left(\mathrm{P}^{*}, \mathrm{dpm} / \mathrm{nmol}\right)$ was then calculated as follows: $\mathrm{P}^{*}=$ [tissue-free ${ }^{3} \mathrm{H}-\mathrm{Pro}-\mathrm{OH}(\mathrm{dpm} / \mathrm{g})+$ protein-bound ${ }^{3} \mathrm{H}-\mathrm{Pro}-\mathrm{OH}$ $(\mathrm{dpm} / \mathrm{g})] /[$ tissue-free Pro-OH $(\mathrm{nmol} / \mathrm{g})+$ protein-bound Pro-OH $(\mathrm{nmol} / \mathrm{g})]$.

Calculation of total $L V$ procollagen synthetic and degradative rates. LV procollagen fractional synthetic rates $\left(K_{\mathrm{s}}, \% / \mathrm{d}\right)$ were calculated using the following equation (15):

\section{LV procollagen Ks}

$$
=\frac{\mathrm{P}^{*}}{\mathrm{~F}^{*}\left(1-e^{-\mathrm{K}^{\prime} t}\right) \times\left(\frac{t}{1-e^{-\mathrm{K}^{\prime} t}-\frac{1}{K^{\prime}}}\right)} \times 100,
$$

where $\mathrm{P}^{*}$ is the total tissue Pro-OH specific radioactivity, $\mathrm{F}^{*}$ is the plasma Pro specific radioactivity at the end of the flooding infusion, $t$ is labeling time in days, and $K^{\prime}$ is a first-order rate constant describing the rate of equilibration of cardiac prolyl-tRNA with plasma Pro (113.62 $\left.\mathrm{d}^{-1}\right)(15)$. Fractional synthetic rates were converted to actual LV procollagen synthetic rates ( $\mathrm{Rs}, \mu \mathrm{g} / \mathrm{d}$ per LV) by multiplying Ks and the total LV collagen content for each animal. Total LV collagen content $(\mathrm{mg} / \mathrm{LV})$ was calculated as follows: $\mathrm{LV}$ Collagen Content $(\mathrm{mg})=[\mathrm{LV}$ weight $(\mathrm{g}) \times$ total Pro-OH $(\mu \mathrm{mol} / \mathrm{g}) \times 0.131(\mu \mathrm{g} / \mu \mathrm{mol})] / 134$.

The fraction of newly synthesized procollagens that was rapidly degraded ( $\mathrm{Fr}, \%)$ was estimated as follows: $\mathrm{Fr}=\left[\right.$ tissue-free ${ }^{3} \mathrm{H}-\mathrm{Pro}-\mathrm{OH}$ $(\mathrm{dpm} / \mathrm{g})] /\left[\right.$ tissue-free ${ }^{3} \mathrm{H}-\mathrm{Pro}-\mathrm{OH}(\mathrm{dpm} / \mathrm{g})+$ protein-bound ${ }^{3} \mathrm{H}-$ Pro$\mathrm{OH}(\mathrm{dpm} / \mathrm{g})] \times 100$. The major assumption in calculating Fr is that all of the Pro-OH in the tissue-free pool (in the form of free amino acid and ethanol-soluble oligopeptides that are produced during the rapid degradation of newly synthesized procollagens) remains in this soluble pool and does not diffuse from the cardiac tissue during the period of the flooding infusion (24).
Other biochemical analyses. LV total protein content and DNA content were determined as previously described (27).

Data analysis. Unless otherwise stated, all results were expressed as mean \pm SEM. Normality was assessed using the Wilk-Shapiro test, and homogeneity of variance was established with Levine's test. Two-way ANOVA was used to compare the factors of age and hypertension on measurements of growth and collagen accumulation. One-way ANOVA followed by Dunnett's test was used for comparisons between multiple groups. The unpaired $t$ test and the Wilcoxon Mann-Whitney test were used for comparisons between two groups. Data were analyzed using the PROPHET computer system (Division of Research Resources, National Institutes of Health).

\section{Results}

Suprarenal aortic coarctation produced hypertension and mild $L V$ hypertrophy. As seen in Fig. 1, constriction of the abdominal aorta of juvenile rats produced a significant increase in MAP within 1 wk after surgery as compared with sham-operated control animals ( $P<0.01$, Dunnett's test $)$. Thereafter, MAP remained elevated during the entire 16-wk observation period. As seen in Table I, both normotensive and hypertensive rats gained weight after surgery. Only after 8 wk was the body weight of banded hypertensive animals somewhat less than that observed for sham-operated controls. Whereas normal cardiac growth was observed in the sham-operated rats, the sustained increase in MAP of banded animals was associated with the development of mild cardiac hypertrophy. A 13\% increase in actual LV weight and a $16 \%$ increase in LV/body weight ratio were apparent as early as $1 \mathrm{wk}$ after banding. Although

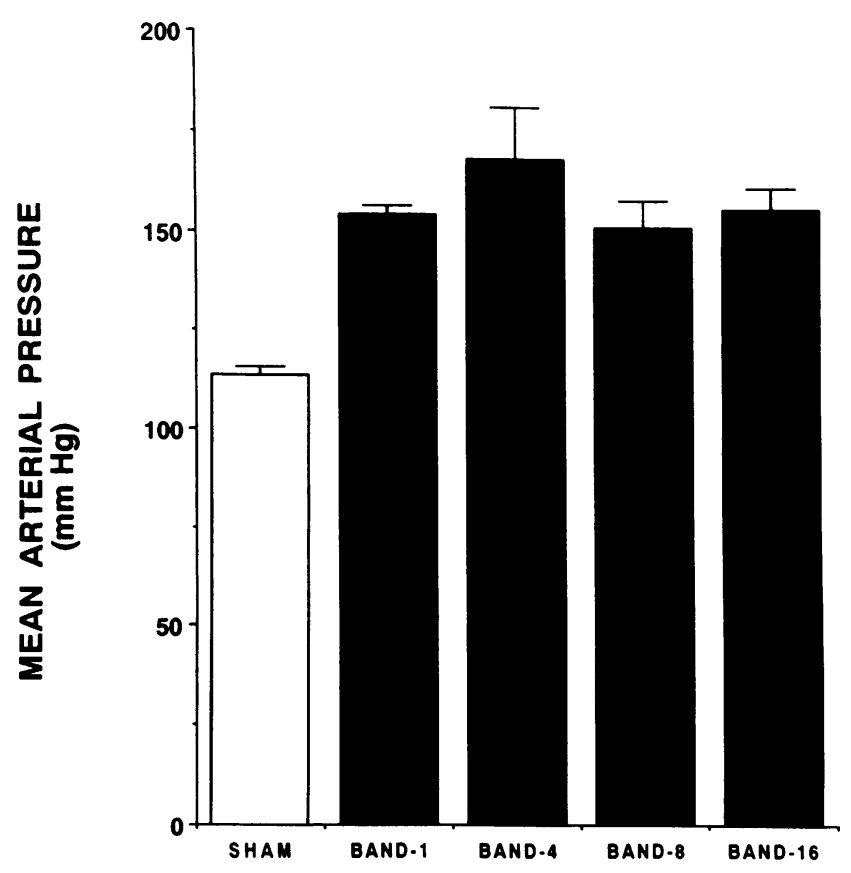

Figure 1. Hypertension induction after suprarenal abdominal aortic coarctation. MAP was recorded from an indwelling carotid artery catheter 1, 4, 8, and $16 \mathrm{wk}$ after abdominal aortic coarctation (filled bars; mean \pm SEM; $n=4-8$ animals in each group) and in shamoperated controls (open bar). Data for the three to four sham-operated animals at each time point were pooled. Results were compared by one-way ANOVA followed by Dunnett's test. MAP in all banded groups was significantly different $(P<0.05)$ from the sham-operated controls. 
Table I. Heart and Body Weight Changes in Sham-operated and Hypertensive Rats

\begin{tabular}{|c|c|c|c|c|c|c|c|c|c|c|}
\hline & \multicolumn{2}{|c|}{ Week 1} & \multicolumn{2}{|c|}{ Week 2} & \multicolumn{2}{|c|}{ Week 4} & \multicolumn{2}{|c|}{ Week 8} & \multicolumn{2}{|c|}{ Week 16} \\
\hline & $\mathbf{S}$ & B & $\mathbf{S}$ & B & $\mathbf{S}$ & B & $\mathbf{S}$ & B & $\mathbf{S}$ & B \\
\hline No. of animals & 9 & 12 & 6 & 7 & 6 & 11 & 6 & 6 & 6 & 5 \\
\hline Initial body weight $(g)$ & $163 \pm 4$ & $167 \pm 3$ & $160 \pm 3$ & $156 \pm 2$ & $162 \pm 1$ & $164 \pm 2$ & $165 \pm 3$ & $171 \pm 2$ & $167 \pm 2$ & $163 \pm 1$ \\
\hline Terminal body weight $(g)$ & $205 \pm 7$ & $198 \pm 4$ & $246 \pm 7$ & $242 \pm 4$ & $327 \pm 4$ & $322 \pm 4$ & $399 \pm 7$ & $366 \pm 13^{*}$ & $504 \pm 11$ & $457 \pm 13^{*}$ \\
\hline Total heart weight $(m g)$ & $751 \pm 23$ & $839 \pm 31$ & $884 \pm 6$ & $1,023 \pm 38$ & $1,112 \pm 36$ & $1,162 \pm 34$ & $1,431 \pm 44$ & $1709 \pm 59 \S$ & $1,532 \pm 69$ & $1,774 \pm 170$ \\
\hline LV weight $(m g)$ & $495 \pm 13$ & $561 \pm 21$ & $540 \pm 32$ & $605 \pm 9$ & $750 \pm 23$ & $804 \pm 28$ & $841 \pm 23$ & $1034 \pm 47 \S$ & $1,007 \pm 49$ & $1,183 \pm 81$ \\
\hline $\mathrm{RV}$ weight $(m g)$ & $145 \pm 9$ & $148 \pm 8$ & $157 \pm 17$ & $178 \pm 11$ & $206 \pm 7$ & $217 \pm 5$ & $233 \pm 10$ & $253 \pm 10$ & $283 \pm 15$ & $336 \pm 56$ \\
\hline LV/body weight $(m g / g)$ & $2.43 \pm .03$ & $2.83 \pm .08 \S$ & $2.21 \pm .14$ & $2.50 \pm .04$ & $2.29 \pm .05$ & $2.50 \pm .09$ & $2.11 \pm .06$ & $2.84 \pm .16^{*}$ & $2.00 \pm .08$ & $2.59 \pm .15 \S$ \\
\hline $\mathrm{RV} /$ body weight $(\mathrm{mg} / \mathrm{g}$ ) & $0.71 \pm .03$ & $0.75 \pm .03$ & $0.64 \pm .07$ & $0.73 \pm .04$ & $0.63 \pm .02$ & $0.67 \pm .12$ & $0.59 \pm .02$ & $0.70 \pm .04^{*}$ & $0.56 \pm .02$ & $0.73 \pm .12$ \\
\hline
\end{tabular}

Data are mean \pm SEM of sham-operated (S) and banded (B) rats. Data at each time point after surgery were compared by unpaired $t$ test or Mann-Whitney test where appropriate. ${ }^{*} P<0.05 ; \S P<0.01$ vs. sham-operated animals.

LV and RV/body weight ratios decreased in the sham-operated animals with increasing age, both indexes remained relatively constant in the hypertensive rats. Thus suprarenal aortic coarctation in young growing animals produced a moderate degree of LV pressure overload, as well as a disproportionate increase in cardiac mass.

Suprarenal aortic coarctation produced disproportionate LV collagen accumulation. $\mathrm{LV}$ total protein concentration was relatively constant over time in both groups $(160-180 \mathrm{mg} / \mathrm{g}$ wet wt), indicating that the modest increase in LV mass observed in banded compared with sham-operated animals was the result of an increased rate of total protein accumulation ( $P$ $<0.001$ for factor hypertension, two-way ANOVA) (Fig. $2 A$ ). LV DNA content (Fig. $2 B$ ) in both normotensive and hypertensive animals increased with increasing age $(P<0.0001$ for factor age, two-way ANOVA). However, mean LV DNA content was consistently greater in banded animals at each time point. These data indicated that, in the absence of significant myocytic polyploidy, some degree on nonmuscle cellular hyperplasia occurred in both groups (banded $>$ sham $)(P<0.001$ for factor hypertension, two-way ANOVA). The cellular hyperplasia in both sham and banded animals was associated with an age-dependent increase in LV collagen content ( $P$ $<0.0001$ for factor age, two-way ANOVA) and an age-dependent increase in the relative concentration of $\mathrm{LV}$ collagenous proteins (Fig. $2 C$ ). LV collagen content of banded animals was consistently greater than sham-operated controls at each time point $(P<0.001$ for factor hypertension, two-way ANOVA). Furthermore, collagens accumulated disproportionately within 1 wk after banding $(2.5 \pm 0.1$ vs. $1.7 \pm 0.2 \%$ of total LV protein for banded vs. sham-operated rats, respectively; $P$ $<0.05$, unpaired $t$ test). Differences in the percent of LV collagenous proteins disappeared within 2 wk after suprarenal banding, only to reappear 16 wk after surgery. Prolonged hypertension ultimately produced a $62 \%$ increase in LV collagen content and a $63 \%$ increase in the percent of total $\mathrm{LV}$ proteins that were collagens.

Suprarenal aortic coarctation produced late interstitial fibrosis. Despite the disproportionate collagen accumulation observed within $1 \mathrm{wk}$ after banding, the histological appearance (using light and transmission electron microscopy) of LV myocardium was relatively normal (Fig. $3 B$ and $4 B$ ). There was no evidence of muscle cell injury, myocytolysis, or inflammation in pressure-overloaded animals. The only histological difference noted between sham and banded animals at this time point was the apparent increase in the number of tissue mast cells surrounding small blood vessels (Fig. $4 \mathrm{~B}$ ). In contrast, numerous focal areas of $\mathrm{LV}$ perivascular and interstitial fibrosis were readily apparent $16 \mathrm{wk}$ after suprarenal coarctation (Figs. $3 \mathrm{D}$ and $4 \mathrm{D}$ ). Increased numbers of tissue mast cells were still apparent, but many showed evidence of degranulation at the site of myocyte loss and reparative fibrosis (Fig. 4 $D)$. Similar pathological findings associated with long-standing hypertension have been observed by other investigators (8-10, 12).

Fibrillar collagen $m R N A$ levels 1,4 , and 16 wks after $L V$ pressure overload. Tissue mRNA levels for $\alpha_{1}$ (I) and $\alpha_{1}$ (III) procollagen polypeptides and GAPDH were analyzed 1,4 , and 16 wk after suprarenal aortic coarctation and compared with
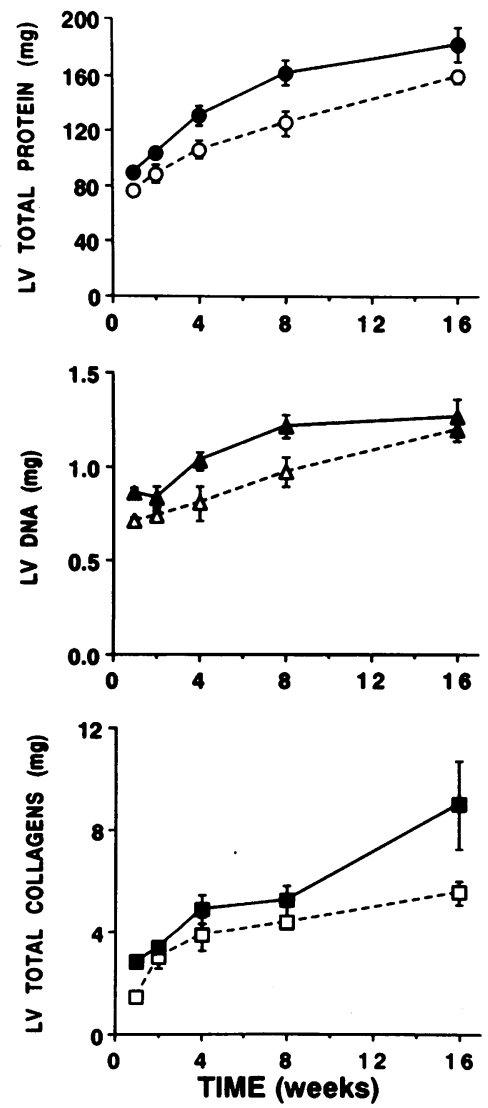

Figure 2. Myocardial tissue composition in hypertensive and shamoperated rats. LV total protein content (top), DNA content (middle), and total collagen content (bottom) were assessed in banded (-) and sham-operated, control animals (- - - -) $1,2,4,8$, and 16 wk after surgery. Data are mean \pm SEM; $n=5-12$ animals in each group at each time point. 

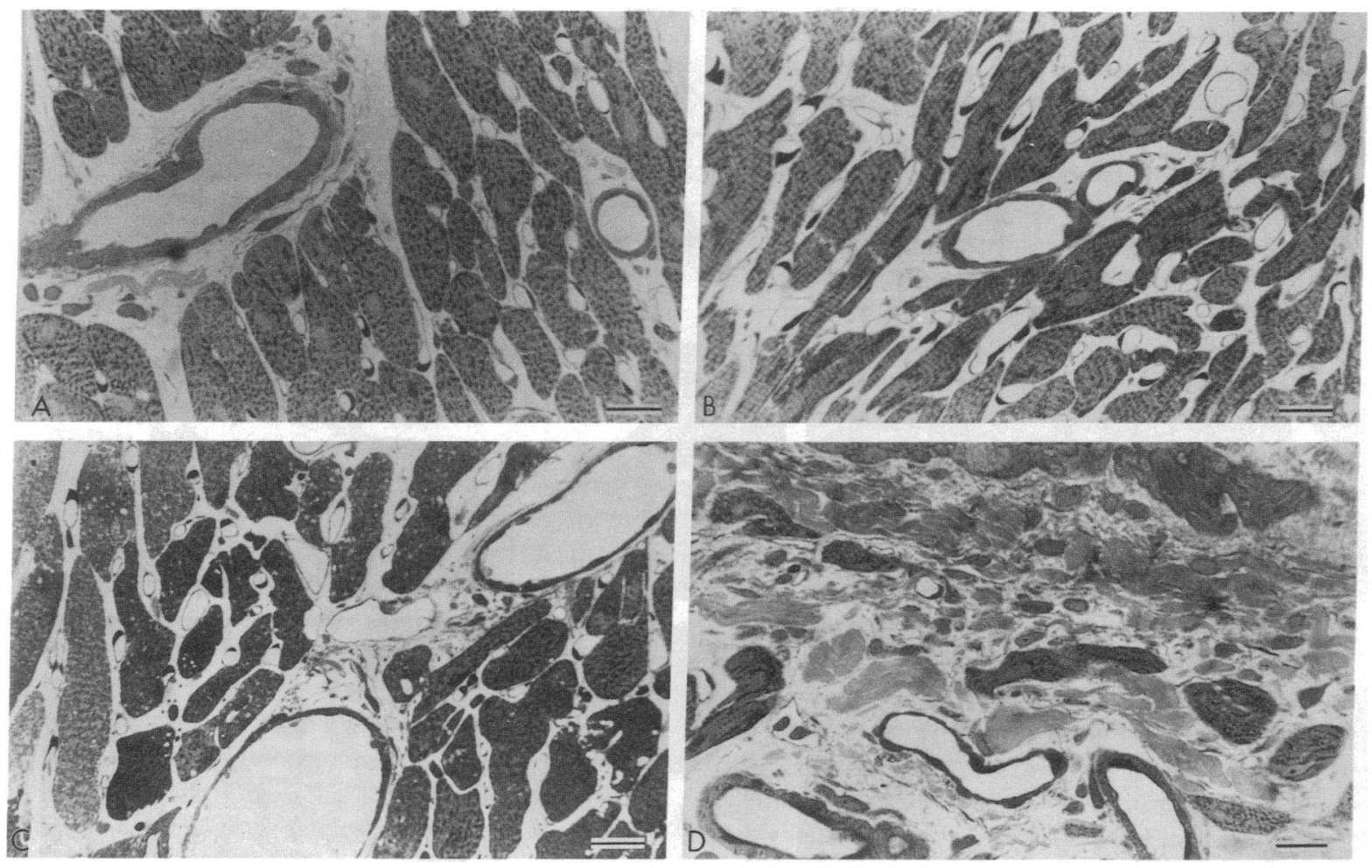

Figure 3. Light microscopic appearance of LV myocardium 1 and 16 wk after suprarenal aortic coarctation. As seen in $A$, LV myocardial tissue from 1-wk sham-operated rats was normal and was not different from tissue sections of hypertensive animals 1 wk after surgery $(B)$. In contrast, numerous focal areas of interstitial and perivascular fibrosis were noted in hypertensive animals 16 wk after surgery $(D)$ as compared with sham-operated controls at the same time point $(C)$. All sections were 1- $\mu \mathrm{m}$ thick and stained with toluidine blue. Bar, $5 \mu \mathrm{m}$.

those observed in sham-operated controls. As seen in Fig. 5, steady state mRNA levels for $\alpha_{1}$ (I) and $\alpha_{1}$ (III) procollagen polypeptides ( representing the major fibrillar collagen types in ventricular myocardium) appeared to be increased $1 \mathrm{wk}$ after aortic coarctation. These results confirm previous findings of Chapman et al. (9) using a similar banding protocol, as well as the results of Villareal and Dillman (11) using thoracic aortic banding in adult rats. However, mRNA levels for GAPDH (which encodes a constitutively expressed glycolytic enzyme present in both the muscle and nonmuscle cell populations of the heart) was also increased in banded versus sham-operated animals. When the abundance of the procollagen transcripts was normalized to differences in the abundance of this arbitrary mRNA, differences in procollagen mRNA levels between 1-wk sham and banded animals were considerably reduced. To further compare relative mRNA levels in sham versus banded animals at the different time points examined $(1,4$, and 16 wk), the same densitometric analysis was performed on films derived from a single Northern blot (containing RNA isolated from three to four animals in each group at each time point). The blot was subsequentially hybridized with the $\alpha_{1}(\mathrm{I})$, $\alpha_{1}$ (III), and GAPDH cDNA probes, and the results are depicted in Fig. 6. As is evident in Fig. $6 A, \alpha_{1}(\mathrm{I})$ mRNA levels (relative to GAPDH mRNA) in sham-operated animals declined with increasing age. In contrast, $\alpha_{1}(\mathrm{I}) \mathrm{mRNA}$ levels in banded animals were similar to sham-operated controls at 1 and $4 \mathrm{wk}$ after surgery, but were six- to sevenfold greater at 16 wk. In addition, normotensive rats demonstrated a relatively constant level of $\alpha_{1}$ (III) mRNA expression, whereas hypertensive rats showed a consistent increase in the level of this procol- lagen transcript at each time point examined (Fig. $6 B$ ). In summary, changes in procollagen mRNA levels varied with both age and the presence of sustained hypertension. Although LV $\alpha_{1}$ (III) mRNA expression was consistently elevated in response to pressure overload, $\alpha_{1}(\mathrm{I}) \mathrm{mRNA}$ levels were increased only after many weeks after abdominal aortic coarctation, and at a time when muscle damage and interstitial fibrosis were readily apparent.

In vivo procollagen synthesis and intracellular procollagen degradation during $L V$ pressure overload. To further examine the relationships between myocardial collagen content and steady state mRNA levels for procollagen polypeptides during LV pressure overload, the proline constant infusion method $(15,16,24)$ was used to assess procollagen biosynthesis at 1,4 , and $16 \mathrm{wk}$ after suprarenal aortic coarctation. As seen in Table II, procollagen synthetic rates ( $R s ; \mu \mathrm{g} / \mathrm{d}$ per $\mathrm{LV}$ ) in sham versus banded animals were similar 1 and 4 wk after aortic coarctation. However, there was a profound increase (threefold) in procollagen synthetic rate $16 \mathrm{wk}$ after surgery in the banded animals as compared with controls. These data correlated reasonably well with the relative mRNA levels for $L V$ procollagen polypeptides when normalized to GAPDH mRNA (Fig. 6) and with the disproportionate collagen accumulation and interstitial fibrosis observed $16 \mathrm{wk}$ after the onset of sustained hypertension.

However, differences in relative procollagen mRNA levels and procollagen synthetic rates did not appear to account for the initially large difference in collagen content between sham and banded animals observed $1 \mathrm{wk}$ after aortic banding. Analysis of the fraction of ${ }^{3} \mathrm{H}$-labeled Pro-OH in the ethanol-soluble, 

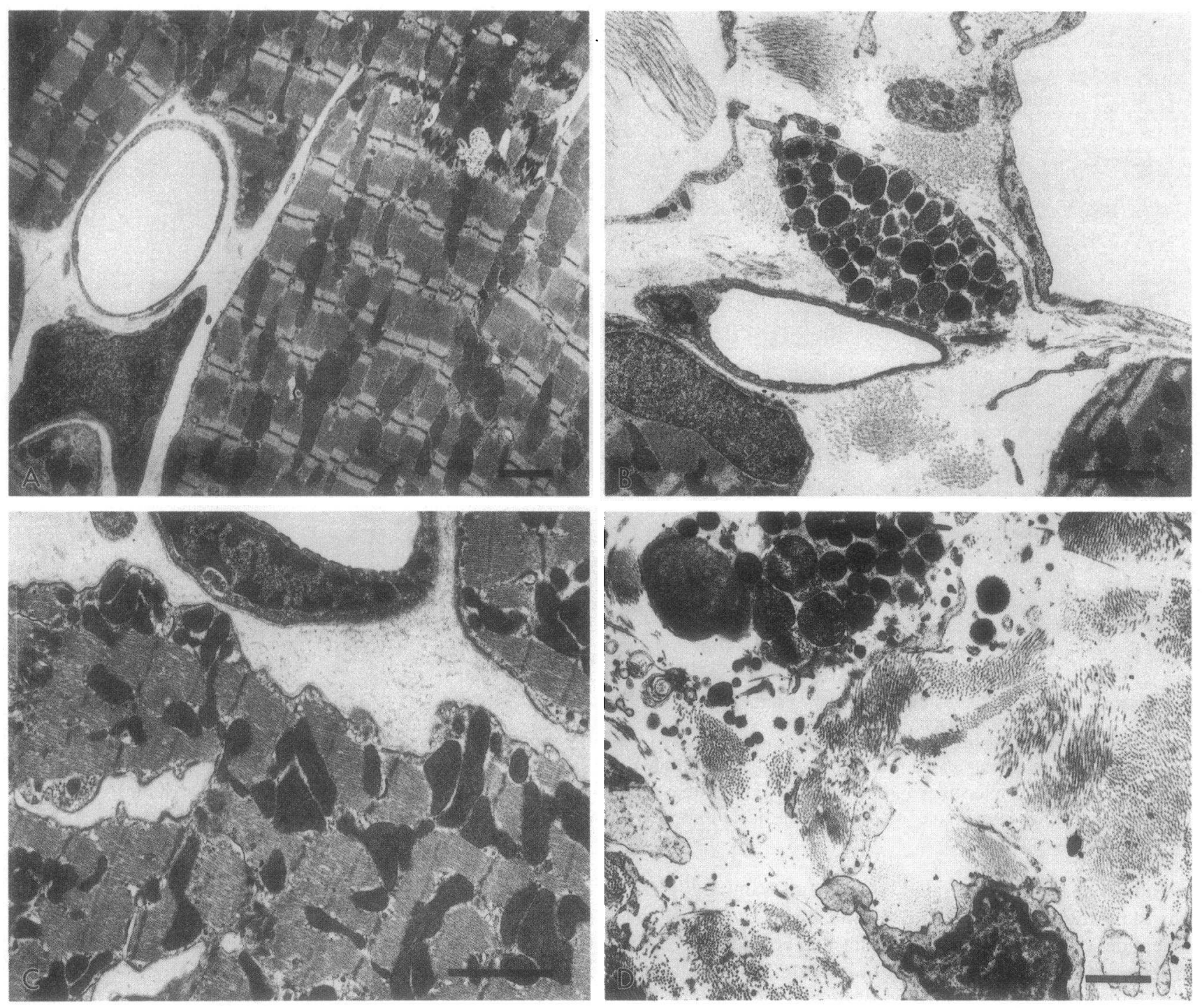

Figure 4. Transmission electron microscopy of LV myocardium 1 and 16 wk after suprarenal aortic coarctation. LV myocardial tissue from 1-wk $(A)$ and 16-wk $(C)$ sham-operated rats was normal. The only difference in tissue sections obtained from 1-wk banded animals $(B)$ was the presence of increased numbers of mast cells surrounding blood vessels. No areas of myocyte necrosis or other inflammatory cell infiltrates were noted. In marked contrast, numerous areas of perivascular and interstitial fibrosis were evident in tissue sections obtained from 16-wk hypertensive rats $(D)$. Increased numbers of tissue mast cells and other mononuclear cells were present within areas of fibrillar collagen deposition. Degenerating muscle cells were also noted. Bar, $2 \mu \mathrm{m}$ for $A-D$.

tissue-free pool in both 1-wk banded and sham-operated controls indicated a major reduction in the fraction of newly synthesized procollagens subject to rapid intracellular degradation (Fr). As seen in Table II, Fr values in pressure-overloaded animals were reduced $\sim 30 \%$ at $1 \mathrm{wk}$. The combination of a modest statistically insignificant increase in procollagen synthesis along with a much larger decrease in the rate of procollagen degradation produced an $87 \%$ increase in LV collagen production ( $54 \pm 6$ vs. $101 \pm 12 \mu \mathrm{g} / \mathrm{d}$ per $\mathrm{LV}$ in sham vs. 1-wk banded animals, respectively; $P<0.05$ ). Thereafter, Fr values in shamoperated animals remained relatively unchanged, whereas $\mathrm{Fr}$ values in banded animals increased with increasing age. Although the markedly increased rate of procollagen synthesis observed $16 \mathrm{wk}$ after coarctation was associated with a $40 \%$ increase in Fr values as compared with controls, net collagen production remained significantly elevated $(40 \pm 1$ vs. $65 \pm 14$ $\mu \mathrm{g} / \mathrm{d}$ per LV in 16 -wk sham vs. banded animals; $P<0.05$ ), thus contributing to the disproportionate collagen accumulation in these hypertensive animals.

\section{Discussion}

Increased collagen deposition and ultrastructural changes in the connective tissue skeleton of LV myocardium has long been considered a causative factor for alterations in cardiac mechanical properties associated with human hypertension and ventricular hypertrophy (6). A variety of experimental animal models have been useful in simulating many of the structural and functional changes associated with human hypertension, with the aim of identifying the cellular mechanisms responsible for the increased deposition of collagenous proteins within the cardiac extracellular matrix of hypertensive patients. As is true for the myofibrillar protein subunits of individ- 


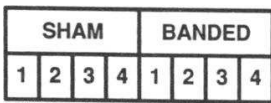

A. $\alpha_{1}(\mathbf{l})$

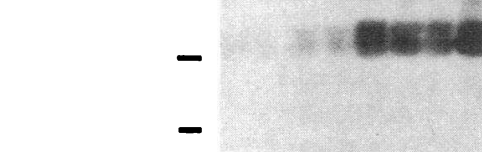

B. $\alpha_{1}$ (III)

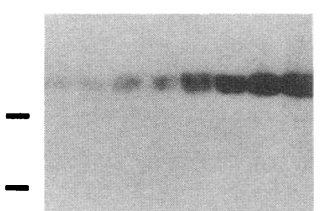

C. GAPDH

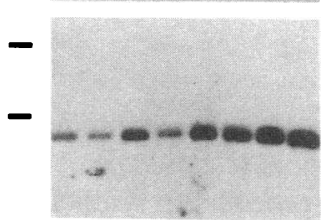

D. 185

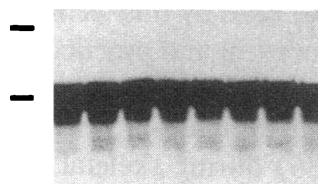

Figure 5. Northern blot analysis of Type I and Type III procollagen mRNAs 1 wk after suprarenal aortic coarctation. $20 \mu \mathrm{g}$ of total LV RNA from four sham and four banded animals was size fractionated on $1 \%$ agarose gels and transferred by capillary action to nylon membranes. The filter was sequentially hybridized with ${ }^{32} \mathrm{P}$-labeled cDNAs encoding $\alpha_{1}(\mathrm{I})$ $(A), \alpha_{1}(\mathrm{III})(B)$, and GAPDH $(C)$. Equal loading conditions were verified by hybridizing the filter with a ${ }^{32} \mathrm{P}$-labeled oligonucleotide probe specific for rat $18 \mathrm{~S}$ rRNA $(D)$. Blots were exposed to Kodak XAR-5 for varying time periods. As is evident from the figure, mRNA levels for both procollagen polypeptides as well as GAPDH were increased in banded as compared with sham-operated controls. The bars to the left in each panel indicate the position of the 28S (upper) and $18 \mathrm{~S}$ (lower) rRNAs.

ual muscle cells, alterations in the rates of accumulation Type I and Type III collagens within the cardiac extracellular matrix must occur because of an imbalance between the rate at which these proteins are synthesized and the rate at which they are degraded. Little information is currently available regarding the regulation of fibrillar procollagen synthesis and turnover by cardiac interstitial cells. Previous reports have indicated that both humoral (28-30) and mechanical factors (31) may be important in regulating steady state mRNA levels encoding fibrillar procollagen genes by cardiac fibroblasts in culture. However, the relationships between tissue procollagen mRNA levels and rates of procollagen biosynthesis and degradation within the LV myocardium in vivo has not been previously explored. On the basis of the data provided in this report, collagen accumulation during normal growth and disproportionate collagen accumulation associated with sustained hypertension may be regulated at a variety of points along the biosynthetic pathway responsible for the deposition of these long-lived extracellular matrix proteins.

Nonocclusive abdominal aortic coarctation in the juvenile rat provided a reliable method for producing moderate sustained hypertension without the acute myocardial injury associated with other forms of experimental pressure overload. In contrast to previous studies of extracellular matrix remodeling in $\mathrm{LV}$ pressure overload produced by thoracic aortic banding $(32,33)$, we found no histological evidence of myocyte injury, necrosis, or replacement fibrosis within the first week after abdominal aortic coarctation. Although an increase in the relative concentration of myocardial collagens was evident soon after imposition of the LV pressure overload, these differences subsequently disappeared as other tissue protein components accumulated. On the basis of the results of our biosynthetic labeling experiments, increased procollagen production during this early phase resulted predominantly from an alteration in the rate of intracellular procollagen degradation rather than a markedly increased rate of procollagen synthesis. Perivascular and interstitial fibrosis (along with disproportionate collagen accumulation and markedly increased procollagen synthetic rates) were observed only after $16 \mathrm{wk}$ of sustained hypertension. In this respect, this animal model more faithfully simulated the connective tissue changes of human myocardium subjected to untreated hypertension. Capasso et al. (10) recently showed that a similar degree of moderate systolic hypertension in the rat, when sustained for a period of $8 \mathrm{mo}$, eventu-

\section{A. $\alpha_{1}(\mathbf{l})$ / GAPDH}

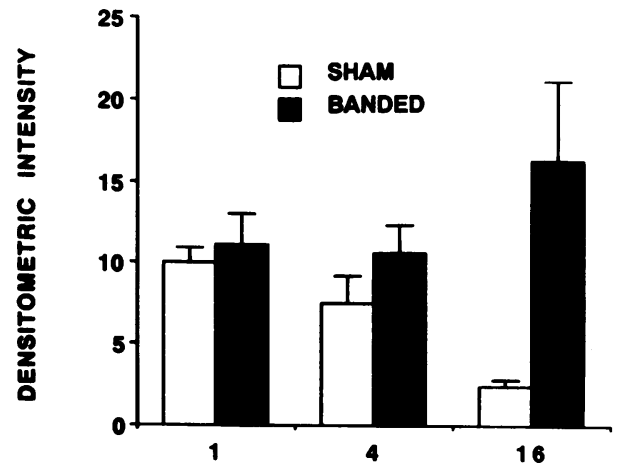

\section{B. $\alpha_{1}$ (III) / GAPDH}

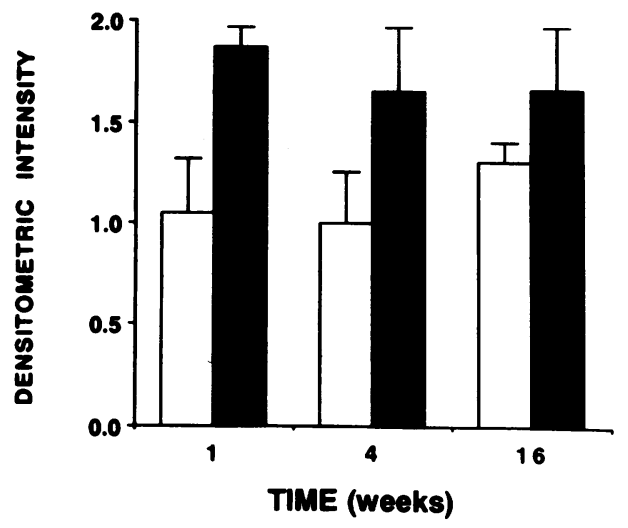

Figure 6. Procollagen mRNA levels 1, 4, and 16 wk after suprarenal aortic coarctation. A single Northern blot (containing $20 \mu \mathrm{g}$ per lane of total LV RNA isolated from three to four animals in each group at each time point ) was sequentially hybridized with $\alpha_{1}(\mathrm{I}), \alpha_{1}$ (III), and GAPDH cDNA probes. The resulting autoradiograms were scanned by laser densitometry, and the densitometric intensity for $\alpha_{1}(\mathrm{I})(A)$, and $\alpha_{1}$ (III) (B) was expressed relative to the band intensity of GAPDH mRNA. As is evident from this figure, $\alpha_{1}(\mathrm{I})$ mRNA levels (relative to GAPDH mRNA) in sham-operated animals (open bars) declined with increasing age. In contrast, $\alpha_{1}(\mathrm{I})$ mRNA levels in banded animals (closed bars) were similar to sham-operated controls at 1 and $4 \mathrm{wk}$ after surgery but were six- to sevenfold greater at 16 wk. In addition, normotensive rats demonstrated a relatively constant level of $\alpha_{1}$ (III) mRNA expression, whereas hypertensive rats showed a consistent increase in the level of this procollagen transcript at each time point examined. 
Table II. Procollagen Synthesis and Degradation in Sham-operated and Hypertensive Rats

\begin{tabular}{|c|c|c|c|c|c|c|}
\hline & \multicolumn{2}{|c|}{ Week 1} & \multicolumn{2}{|c|}{ Week 4} & \multicolumn{2}{|c|}{ Week 16} \\
\hline & S & B & $\mathbf{s}$ & B & $\mathbf{S}$ & B \\
\hline No. of animals & 6 & 9 & 6 & 11 & 6 & 5 \\
\hline $\mathrm{Ks}(\% / d)$ & $10.2 \pm 1.9$ & $7.0 \pm 0.8$ & $4.9 \pm 0.8$ & $4.1 \pm 0.4$ & $1.8 \pm 0.1$ & $4.2 \pm 0.7^{*}$ \\
\hline $\operatorname{Rs}(\mu g / d$ per $L V)$ & $125 \pm 24$ & $143 \pm 12$ & $167 \pm 6$ & $190 \pm 15$ & $100 \pm 8$ & $333 \pm 32^{\S}$ \\
\hline $\operatorname{Fr}(\%)$ & $51 \pm 4$ & $36 \pm 5^{*}$ & $48 \pm 3$ & $50 \pm 3$ & $58 \pm 3$ & $81 \pm 2^{\S}$ \\
\hline $\begin{array}{l}\text { Collagen production } \\
(\mu g / d \text { per } L V)\end{array}$ & $54 \pm 6$ & $101 \pm 12^{*}$ & $86 \pm 6$ & $91 \pm 4$ & $40 \pm 1$ & $65 \pm 14^{*}$ \\
\hline
\end{tabular}

Data are mean \pm SEM of sham-operated (S) and banded (B) rats. Data at each time point after surgery were compared by unpaired $t$ test or Mann-Whitney test where appropriate. ${ }^{\S} P<0.01 ;{ }^{*} P<0.05$ vs. sham-operated animals.

ally led to LV dysfunction and congestive heart failure. Although functional studies were not performed in our experimental animals, the degree of hypertension as well as the histopathology of LV myocardial tissue in both studies suggests that further sustained hypertension in our animals would have led to similar changes in LV function over time. Furthermore, our results support the conclusions of Capasso et al. (10), indicating that time constitutes one of the most significant variables for the development of myocardial interstitial fibrosis and associated contractile dysfunction.

As discussed by Wiesner and Zak (34), the quantitative analysis of changes in mRNA abundance is an important step in identifying the regulatory events responsible for changes in specific gene expression. In a previous study of myocardial collagen gene expression in response to abdominal aortic coarctation, Chapman et al. (9) noted a transient increase in the concentration (relative to total RNA) of mRNAs encoding Type I and Type III procollagen polypeptides during the first week after banding. These data were interpreted as a causal factor in the increased collagen accumulation and interstitial fibrosis observed only after many weeks. Our results confirm the increase in Type I and Type III procollagen mRNA levels relative to total and 18S rRNA soon after hypertension induction, but when the same data were expressed relative to GAPDH mRNA, a constitutively expressed gene transcript (34), these differences were much less apparent. In contrast, normalization of the data in this fashion revealed a much larger increase in Type I procollagen mRNA $16 \mathrm{wk}$ after banding and a persistent increase in mRNA abundance for Type III procollagen throughout the observation period. We believe that normalization of procollagen mRNA levels to a "housekeeping gene" mRNA (such as GAPDH) provides a clearer picture of the regulatory events responsible for procollagen gene expression in the pressure-overloaded heart (35). In this way, other factors, such as differences in the efficiency of tissue mRNA extraction, differences in the concentration of nucleases in fibrotic versus nonfibrotic myocardium, and differences in the relative concentrations of ribosomal versus total mRNAs during LV pressure overload, are accounted for (34).

On the basis of this quantitative analysis of mRNA abundance, we conclude that both pre- and posttranslational mechanisms are responsible for the increased collagen accumulation observed at various stages of LV pressure overload. The flooding infusion results corroborated these findings, as alterations in procollagen intracellular degradation ( $\mathrm{Fr}$ ) appeared to be a major factor in the increased collagen production detected early in sustained hypertension. It should be pointed out, however, that the estimation of procollagen synthetic and intracellular procollagen degradative rates by this technique is dependent upon a number of theoretical and practical assumptions, as outlined by McAnulty and Laurent (24) and Karim et al. (15). Nevertheless, a similar decrease in procollagen Fr was noted by Laurent et al. (36) during skeletal muscle hypertrophy and by Turner et al. (37) during RV hypertrophy after bleomycin-induced lung injury. At present, little is known about the intracellular sites and regulatory events that might modify the susceptibility of newly synthesized procollagens to intracellular proteolysis in vivo. Recently, Nakai et al. (38) found that a molecular chaperone (HSP47) is involved in procollagen assembly and transport within the endoplasmic reticulum of collagen-producing cells. Binding of this protein to Type I procollagen was enhanced by heat stress and treatment with $\alpha, \alpha^{\prime}$-dipyridyl, which inhibited stable triple-helix formation. Whether these interventions also altered procollagen Fr is not known, but the role of HSP47 in intracellular procollagen degradation by cardiac fibroblasts in vivo and in vitro requires further study.

Our observation that $\alpha_{1}$ (III) procollagen mRNA levels were persistently increased in pressure-overloaded myocardium is interesting in light of recent observations by Carver et al. (31), who demonstrated the preferential expression of $\alpha_{1}$ (III) procollagen mRNA and protein by mechanically stimulated cardiac fibroblasts in culture. Our results also provide an explanation for the previously noted increase in the relative proportion of Type III collagen in pressure-overloaded rat (39) and macaque (12) myocardium and indicate that these in vivo changes were also partly regulated at the pretranslational level. Additional studies are needed, however, to determine whether mechanical factors directly regulate $\alpha_{1}$ (III) procollagen mRNA stability and/or transcriptional rate in these collagenproducing cells and to identify all of the steps responsible for mechanochemical signal transduction in cardiac fibroblasts.

We provide clear evidence that the interstitial fibrosis associated with untreated long-standing hypertension is due to a markedly increased rate of procollagen biosynthesis occurring only after many months of pressure overload. Increased procollagen synthetic rates correlated reasonably well with the late increase in mRNA levels for $\alpha_{1}(\mathrm{I})$ procollagen polypeptide, indicating a substantial increase in the expression of this gene by cardiac fibroblasts. Of note, the relative increase in the level 
of this transcript (and to a much lesser extent $\alpha_{1}[$ III $]$ mRNA) far exceeded the rather modest increase in LV DNA content and degree of LV hypertrophy, suggesting the "activation" of Type I procollagen synthesis rather than a major increase in the number of collagen-producing interstitial cells. The mechanisms underlying the deposition of Type I collagen by cardiac fibroblasts are unknown but are likely to be related to reparative fibrosis and "healing" at sites of myocyte necrosis. A potential candidate for mediating this local response is TGF- $\beta_{1}$, which is present in significant amounts in normal and hypertrophied rat heart myocytes $(40,41)$. Release of intracellular stores of TGF- $\beta_{1}$ accompanied experimental myocardial infarction following coronary ligation (40). Activation of latent TGF $-\beta_{1}$ by cellular proteinases in the extracellular space may also occur in response to myocyte injury (42). This peptide has also been shown to increase Type I procollagen mRNA abundance in cultured cardiac fibroblasts (29), presumably by stimulating $\alpha_{1}$ (I) gene transcription (43).

Finally, it should be pointed out that increased cardiac procollagen biosynthesis occurs in other forms of hemodynamic overload producing LV hypertrophy that are not associated with interstitial fibrosis. In a previous report from this laboratory (15), we demonstrated a threefold increase in LV procollagen production after $8 \mathrm{wk}$ of daily thyroxine administration to juvenile rats. Although thyroid hormone administration produced hemodynamic overload and LV hypertrophy, protein-bound Pro-OH concentration in LV tissue actually decreased ( rather than increased ). The absence of disproportionate collagen accumulation and interstitial fibrosis despite markedly increased procollagen synthesis was due to the absence of muscle cell injury and to accelerated turnover of fully processed collagens in the extracellular matrix (15). It is conceivable that alterations in extracellular degradation of fully processed cross-linked collagens may have also contributed to disproportionate collagen accumulation and interstitial fibrosis during abdominal aortic coarctation. Nevertheless, distinct differences in procollagen metabolism characterize "physiological" versus "pathological" hypertrophy, which may be independent of the degree of hemodynamic overload and the level of procollagen gene transcription.

\section{Acknowledgments}

E. G. Eleftheriades and J.-B. Durand made equal scientific contributions to this study. The authors thank Victoria Maloney and Michael Peters for expert technical assistance and Jean Marciniak for help in preparing the manuscript.

These studies were supported by National Heart, Lung, and Blood Institute grants HL-43582, HL-34328, and HL-42218.

\section{References}

1. Caulfield, J. B., and T. K. Borg. 1979. The collagen network of the heart Lab. Invest. 40:364-372.

2. Borg, T. K., and J. B. Caulfield. 1981. The collagen matrix of the heart. Fed. Proc. 40:2037-2041.

3. Eghbali, M., O. O. Blumenfeld, S. Seifter, P. M. Buttrick, L. A. Leinwand, T. F. Robinson, M. A. Zern, and M. A. Giambrone. 1989. Localization of types I, III and IV collagen mRNAs in rat heart cells by in situ hybridization. J. Mol. Cell. Cardiol. 21:103-113.

4. Laurent, G. J. 1987. Dynamic state of collagen: pathways of collagen degradation in vivo and their possible role in regulation of collagen mass. Am. J. Physiol. 252:C1-C9.

5. Eghbali, M., M. Eghbali, T. F. Robinson, S. Seifter, and O. O. Blumenfeld.
1989. Collagen accumulation in heart ventricles as a function of growth and aging. Cardiovasc. Res. 23:723-729.

6. Bing, O. H., S. Matsushita, B. L. Fanburg, and H. J. Levine. 1971. Mechanical properties of rat cardiac muscle during experimental hypertrophy. Circ. Res. 28:234-245.

7. Medugorac, I. 1980. Collagen content in different areas of normal and hypertrophied rat myocardium. Cardiovasc. Res. 14:551-554.

8. Doering, C. W., J. E. Jalil, J. S. Janicki, R. Pick, S. Aghili, C. Abrahams, and K. T. Weber. 1988. Collagen network remodeling and diastolic stiffness of the rat left ventricle with pressure overload hypertrophy. Cardiovasc. Res. 22:686-695.

9. Chapman, D., K. T. Weber, and M. Eghbali. 1990. Regulation of fibrillar collagen types I and III and basement membrane type IV collagen gene expression in pressure overloaded rat myocardium. Circ. Res. 67:787-794.

10. Capasso, J. M., T. Palackal, G. Olivetti, and P. Anversa. 1990. Left ventricular failure induced by long-term hypertension in rats. Circ. Res. 66:1400-1412.

11. Villarreal, F. J., and W. H. Dillmann. 1992. Cardiac hypertrophy-induced changes in mRNA levels for TGF- $\beta_{1}$, fibronectin, and collagen. Am. J. Physiol. H1861-H1866.

12. Weber, K. T., J. S. Janicki, S. G. Shroff, R. Pick, R. M. Chen, and R. I. Bashey. 1988. Collagen remodeling of the pressure-overloaded, hypertrophied nonhuman primate myocardium. Circ. Res. 62:757-765.

13. Raghow, R., and J. P. Thompson. 1989. Molecular mechanisms of collagen gene expression. Mol. Cell. Biochem. 86:5-18.

14. Bienkowski, R. S. 1983. Intracellular degradation of newly synthesized secretory proteins. Biochem. J. 214:1-10.

15. Karim, M. A., A. G. Ferguson, B. T. Wakim, and A. M. Samarel. 1991. In vivo collagen turnover during development of thyroxine-induced left ventricular hypertrophy. Am. J. Physiol. 260:C316-C326.

16. Laurent, G. J. 1982. Rates of collagen synthesis in lung, skin and muscle obtained in vivo by a simplified method using $\left[{ }^{3} \mathrm{H}\right]$ proline. Biochem. J. 206:535544.

17. Chomczynski, P., and N. Sacchi. 1987. Single-step method of RNA isolation by acid guanidinium thiocyanate-phenol-chloroform extraction. Anal. Biochem. 162:156-159.

18. Chu, M. L., J. C. Myers, M. P. Bernard, J. F. Ding, and F. Ramirez. 1982. Cloning and characterization of five overlapping cDNAs specific for the human pro $\alpha_{1}(\mathrm{I})$ collagen chain. Nucleic Acids Res. 10:5925-5934.

19. Chu, M. L., D. Weil, W. de Wet, M. Bernard, M. Sippola, and F. Ramirez. 1985. Isolation of $\mathrm{cDNA}$ and genomic clones encoding human pro- $\alpha_{1}$ (III) collagen. J. Biol. Chem. 260:4357-4363.

20. Tso, J. Y., X. H. Sun, T. Kao, K. S. Reece, and R. Wu. 1985. Isolation and characterization of rat and human glyceraldehyde-3-phosphate dehydrogenase cDNAs: genomic complexity and molecular evolution of the gene. Nucleic Acids Res. 13:2485-2502.

21. Chan, Y. L., R. Gutell, H. F. Noller, and I. G. Wool. 1984. The nucleotide sequence of a rat $18 \mathrm{~S}$ ribosomal ribonucleic acid gene and a proposal for the secondary structure of $18 \mathrm{~S}$ ribosomal ribonucleic Acid. J. Biol. Chem. 259:224230 .

22. Engelmann, G. L., J. C. Vitullo, and R. G. Gerrity. 1987. Morphometric analysis of cardiac hypertrophy during development, maturation and senescence in spontaneously hypertensive rats. Circ. Res. 60:487-494.

23. Airhart, J., J. Kelley, J. E. Brayden, and R. B. Low. 1979. An ultramicro method of amino acid analysis: application to studies of protein metabolism in cultured cells. Anal. Biochem. 96:45-55.

24. McAnulty, R. J., and G. J. Laurent. 1987. Collagen synthesis and degradation in vivo. Evidence for rapid rates of collagen turnover with extensive degradation of newly synthesized collagen in tissues of the adult rat. Collagen Relat. Res. 7:93-104.

25. Woessner, J. F., Jr. 1961. The determination of hydroxyproline in tissue and protein samples containing small proportions of this imino acid. Arch. Biochem. Biophys. 93:440-447.

26. Stimler, N. P. 1984. High-performance liquid chromatographic quantitation of collagen biosynthesis in explant cultures. Anal. Biochem. 142:103-108.

27. Samarel, A. M. 1989. Regional differences in the in vivo synthesis and degradation of myosin subunits in rabbit ventricular myocardium. Circ. Res. 64:193-202.

28. Chua, C. C., B. H. Chua, Z. Y. Zhao, C. Krebs, C. Diglio, and E. Perrin. 1991. Effect of growth factors on collagen metabolism in cultured human heart fibroblasts. Connect. Tissue Res. 26:271-281.

29. Eghbali, M., R. Tomek, V. P. Sukhatme, C. Woods, and B. Bhambi. 1991 Differential effects of transforming growth factor- $\beta_{1}$ and phorbol myristate acetate on cardiac fibroblasts; regulation of fibrillar collagen mRNAs and expression of early transcription factors. Circ. Res. 69:483-490.

30. Zeydel, M., K. Puglia, M., Eghbali, J. Fant, S. Seifter, and O. O. Blumenfeld. 1991. Properties of heart fibroblasts of adult rats in culture. Cell Tissue Res. 265:353-359.

31. Carver, W., M. L. Nagpal, M. Nachtigal, T. K. Borg, and L. Terracio. 1991. Collagen expression in mechanically stimulated cardiac fibroblasts. Circ. Res. 69:116-122.

32. Bishop, S. P., and L. R. Melsen. 1976. Myocardial necrosis, fibrosis, and 
DNA synthesis in experimental cardiac hypertrophy induced by sudden pressure overload. Circ. Res. 39:238-244.

33. Contard, F., V. Koteliansky, F. Marotte, I. Dubus, L. Rappaport, and J. L. Samuel. 1991. Specific alterations in the distribution of extracellular matrix components within rat myocardium during the development of pressure overload. Lab. Invest. 64:65-75.

34. Wiesner, R. J., and R. Zak. 1991. Quantitative approaches for studying gene expression. Am. J. Physiol. 260:L179-L188.

35. Takahashi, T., H. Schunkert, S. Isoyoma, J. Y. Wei, B. Nadal-Ginard, W. Grossman, and S. Izumo. 1992. Age-related differences in the expression of proto-oncogene and contractile protein genes in response to pressure overload in the rat myocardium. J. Clin. Invest. 89:939-946.

36. Laurent, G. J., R. J. McAnulty, and J. Gibson. 1985. Changes in collagen synthesis and degradation during skeletal muscle growth. Am. J. Physiol. 249:C352-C355.

37. Turner, J. E., M. H. Oliver, D. Guerreiro, and G. J. Laurent. 1986. Collagen metabolism during right ventricular hypertrophy following induced lung injury. Am. J. Physiol. 251:H915-H919.

38. Nakai, A., M. Satoh, K. Hirayoshi, and K. Nagata. 1992. Involvement of the stress protein HSP47 in procollagen processing in the endoplasmic reticulum. J. Cell Biol. 117:903-914.

39. Borg, T. K., and L. T. Terracio. 1990. Interaction of the extracellular matrix with cardiac myocytes during development and disease. In Cardiac Myocyte-Connective Tissue Interactions in Health and Disease. T. F. Robinson, and R. K. Kinnel, editors. Vol. 13. A. G. Karger, Basel, Switzerland. 113-129.

40. Casscells, W., F. Bazoberry, E. Speir, N. Thompson, K. Flanders, P Kondaiah, V. J. Ferrans, S. E. Epstein, and M. Sporn. 1990. Transforming growth factor- $\beta$ in normal heart and in myocardial infarction. Ann. NY Acad. Sci. 593:148-160.

41. Engelmann, G. L., K. D. Boehm, M. C. Birchenall-Roberts, and F. W. Ruscetti. 1992. Transforming growth factor-beta in heart development. Mech. Dev. 38:85-98.

42. Sporn, M. B., A. B. Roberts, L. M. Wakefield, and B. de Crombrugghe. 1987. Some recent advances in the chemistry and biology of transforming growth factor-beta. J. Cell Biol. 105:1039-1045.

43. Ritzenthaler, J. D., R. H. Goldstein, A. Fine, A. Lichtler, D. W. Rowe, and B. D. Smith. Transforming-growth-factor- $\beta$ activation elements in the distal promoter regions of the rat $\alpha 1$ type I collagen gene. Biochem. J. 280:157-162. 